\title{
HANNAH ARENDT EM DIÁLOGO COM A FENOMENOLOGIA: SARTRE, MERLEAU-PONTY E A TRAMA ENTRE LIBERDADE E TEMPORALIDADE*
}

\section{HANNAH ARENDT DIALOGUE WITH PHENOMENOLOGY: SARTRE, MERLEAU-PONTY AND THE PLOT BETWEEN FREEDOM AND TEMPORALITY}

\author{
Alex de Campos Moura \\ https://orcid.org/0000-0002-5867-0774 \\ alexmoura@usp.br \\ Universidade de São Paulo, Brasil
}

RESUMO Neste ensaio, discutiremos o modo como a relação entre liberdade e temporalidade aparece em momentos determinados da reflexão de Hannah Arendt, Sartre e Merleau-Ponty, tomando como eixo de investigação a maneira pela qual cada um deles concebe a articulação entre permanência e mudança na descrição da dinâmica temporal. Com isso, pretende-se estabelecer um horizonte de convergência e, em seu interior, explicitar dois encaminhamentos distintos para uma questão similar, mostrando como é possível estabelecer um eixo fenomenológico comum e, ao mesmo tempo, explicitar a diversidade que o constitui.

* Artigo submetido em 11/07/2020. Aprovado em 26/11/2020. 
Palavras-chave Liberdade. Temporalidade. Fenomenologia. Hannah Arendt. Sartre. Merleau-Ponty.

ABSTRACT In this essay, we will discuss the way in which the relationship between freedom and temporality appears at certain moments of Hannah Arendt, Sartre and Merleau-Ponty reflections, taking the way in which each of them conceives the articulation between permanence and change in time dynamics as an axis of investigation. With this, it is intended to establish a horizon of convergence and, within it, to make explicit two different approaches to a similar issue, showing how it is possible to establish a common phenomenological axis and, at the same time, explain the diversity that constitutes it.

Keywords Freedom. Temporality. Phenomenology. Hannah Arendt. Sartre. Merleau-Ponty.

Neste ensaio, discutiremos o modo como a relação entre liberdade e temporalidade é compreendida por três importantes autores do pensamento contemporâneo, tomando como eixo de nossa investigação a articulação entre permanência e mudança descrita por cada um deles. Em um primeiro momento, discutirmos a formulação proposta por Hannah Arendt em seu livro A Condição Humana ${ }^{1}$, explicitado uma perspectiva que permanece latente em suas descrições. Passaremos, em seguida, ao estudo de Sartre e Merleau-Ponty, concentrando-nos especialmente em $O$ Ser e o Nada e a Fenomenologia da Percepção, mostrando como cada um deles, em meio a um profundo diálogo, propõe compreensões quase antagônicas sobre o tema.

Por meio desse percurso, procuraremos mostrar a presença de um horizonte comum de entendimento entre os autores e, no interior deste, circunscrever duas soluções distintas para uma questão similar, explicitando compreensões diversas sobre a temporalidade. Poderemos, assim, propor uma proximidade significativa entre a reflexão de Arendt e um importante eixo do pensamento

1 Neste ensaio, nos concentraremos especialmente nesta obra e em algumas referências de Entre o Passado e o Futuro. Evidentemente, não pretendemos aqui esgotar o tema da liberdade, extremamente vasto e complexo ao longo da obra da autora, e tampouco sua abordagem sobre a temporalidade, questão igualmente densa e presente, sob diferentes modos, no decorrer de toda sua reflexão - que se lembre, por exemplo, de sua discussão sobre a relação entre tempo e pensamento em A Vida do Espírito. Nossa proposta, ao contrário, é circunscrever um eixo específico presente nessa articulação, investigando-o a partir do campo delimitado por três operadores específicos, que serão tematizados neste ensaio: o perdão, o milagre e a promessa. 
fenomenológico ${ }^{2}$ e, ao mesmo tempo, explicitar a diversidade que se assenta por sob esse eixo, mostrando como uma perspectiva fenomenológica comum não implica identidade de formulações.

\section{O milagre, o perdão e a promessa}

Em A Condição Humana - texto base de nossa análise - Arendt descreve um movimento histórico vasto, mas bastante coeso, por meio do qual o sentido original da política ocidental foi gradualmente pervertido ${ }^{3}$. Trata-se da explicitação do modo pelo qual a política foi historicamente desconfigurada, em nome da expansão de uma dinâmica social organizada segundo relações de dominação e de "governo". Partindo da experiência greco-romana, a autora acompanha o processo complexo e gradual através do qual uma experiência originária de liberdade e de igualdade se converteu em um modelo de opressão e de força, culminando com a formação de regimes apolíticos e autoritários. Nesse processo, uma das principais mudanças seria a perda de uma das características fundamentais do que se entendia, originariamente, como política (e, não por acaso, um traço surpreendente para o pensamento contemporâneo): sua vinculação intrínseca com três capacidades humanas: o milagre, a promessa e o perdão - experiências deslocadas, posteriormente, para o campo teológico.

2 Há diversos autores que trabalham essa questão, especialmente a relação da autora com o pensamento heideggeriano. Consideramos, contudo, haver ainda um vasto campo a ser explorado sobre a dimensão fenomenológica presente em A Condição Humana. Particularmente, Benhabib, em seu ensaio Teoria feminista e o conceito de espaço público de Hannah Arendt (Benhabib, 1993), chama a atenção para uma espécie de "essencialismo fenomenológico" presente na obra, em parte responsável pela rigidez com a qual a autora constrói suas distinções. Embora sigamos em larga medida a leitura ali proposta por Benhabib, especialmente em sua contraposição às interpretações de Pitkin sobre a noção de espaço público em Arendt (Pitkin, 1981, pp. 327-352), não a acompanhamos neste ponto em particular. Como pretendemos mostrar, parece-nos que um dos caminhos por meio dos quais a fenomenologia entra em $A$ Condição Humana é através de uma discussão fundamentalmente política e, por isso mesmo, incontornavelmente relacionada à história. A conceitualização dos termos envolve simultaneamente sua problematização histórica - característica que, se não anula inteiramente algum essencialismo presente nas reflexões da autora, certamente o atenua.

André Duarte, em seu ensaio Poder, violência e revolução no pensamento político de Hannah Arendt, por caminho diverso ao que aqui propomos, também recusa a ideia de um essencialismo ou de uma rigidez exacerbada nas categorias propostas por Arendt (Duarte, 2016).

3 De acordo com a proposta deste estudo, o que apresentaremos são as linhas gerais da retomada histórica apresentada por Arendt em A Condição Humana. A questão, no interior de sua obra, pode ser abordada de inúmeros modos, inclusive através de sua descrição de experiências que escapam a este movimento geral - preservando a possibilidade de configuração de um espaço público -, como determinados momentos de movimentos revolucionários e como as experiências de associações ou conselhos participativos. Contudo, para a questão aqui em foco, o importante é tornar explícito o modo pelo qual o sentido originário da política envolvia, de maneira intrínseca, o perdão, a promessa e a ação, já que é essa articulação que nos permitirá retraçar, conceitualmente, os elos entre liberdade e temporalidade. Não se trata, como descrito na nota anterior, de afirmar um caráter essencialista ou fatalista nas noções apresentadas pela autora, mas de reconhecer algo de irredutível nelas. 
São elas, como veremos neste ensaio, que guardavam aquilo que era mais próprio e essencial para a experiência política autêntica: a liberdade, entendida não como exercício da vontade ou da razão, mas como ação, acontecimento humano que se realizava entre agentes desobrigados da necessidade, igualmente dispostos em um espaço plural e público.

Para começarmos a circunscrever essa concepção de liberdade, cabe recorrer aqui à noção de espaço público proposta por Arendt, ela própria uma explicitação de como a política, em seu sentido original, mantinhase desvinculada de qualquer experiência administrativa ou institucional, exigindo um campo de configuração diverso. Aquilo que a contemporaneidade compreende como político - um grande corpo social articulado em torno da ideia de um Estado que opera como administrador e gerenciador de interesses particulares ${ }^{4}$-, é visto por ela como uma distorção de princípio, que teria na perda da noção de público uma de suas características mais marcantes. No movimento de degradação do sentido da política, um fator crucial teria sido a dissolução daquilo que os antigos consideravam uma de suas garantias centrais (Arendt, 1987): a delimitação do espaço público e sua sólida distinção em relação ao espaço privado.

Apoiando-se na descrição da polis, Arendt mostra que, originariamente ${ }^{5}$, havia uma distância clara entre o que obedecia à lógica do público e o que se configurava segundo a dinâmica do privado. Na verdade, ambos se estruturavam pela diferenciação que estabeleciam entre si. O privado equivalia ao campo da existência organizada segundo as demandas da necessidade e da sobrevivência. Nele, cuidava-se das exigências da vida e de sua conservação, das carências que precisavam ser supridas por meio do trabalho e, sobretudo, do labor ${ }^{6}$. Constituído segundo esse imperativo, ele desconhecia a igualdade entre sujeitos, estabelecendo-se de acordo com relações de hierarquia e de dominação. $\mathrm{O}$ exemplo mais nítido era o da família, em que o pai, enquanto detentor da força, assumia o comando sobre os demais, em nome da preservação e da subsistência

4 A noção de social é amplamente desenvolvida pela autora, inserida em uma longa crítica a respeito do processo de perda de sentido da política ao longo da história ocidental. A esse respeito ver O relutante modernismo de Hanna Arendt, de Benhabib, especialmente seu ensaio A destruição da Esfera Pública e a Emergência do Totalitarismo, e Poder, violência e revolução no pensamento político de Hannah Arendt, de André Duarte.

5 Em A Condição Humana e outros textos próximos, a autora toma a experiência da polis como experiência referencial, próxima de um sentido "originário" da política. Evidentemente, não se trata de afirmar a polis como "ideal" a se perseguir e, nem mesmo, como modelo a ser reproduzido. Muitas das críticas sofridas pela autora nos parecem resultado da incompreensão a respeito do modo como ela entende e mobiliza a história. Sobre esse ponto, sobre sua compreensão e relação com a história, e sobre o modo como ela logra estabelecer um diálogo rigoroso e original com a Tradição, ver Benhabib (especialmente seu ensaio The Destruction of the Public Sphere and the Emergence of Totalitarism, In: Benhabib, 1996). Aqui, trabalharemos brevemente essa questão, ao discutirmos sua apropriação do pensamento de Agostinho.

6 Seguimos, aqui, a terminologia proposta pela tradução de Roberto Raposo (Arendt, 1987). 
do grupo. Regido pela necessidade, esse espaço se caracterizava por relações de "governo" e de desigualdade entre seus membros.

Responsável, contudo, pela satisfação do necessário e pela preservação da vida, ele se mantinha imprescindível para a existência do espaço público, pois apenas quando as necessidades privadas estavam satisfeitas e o homem tinha um "lugar" no mundo, sua casa, é que ele podia efetivamente assumir uma existência pública. Essa, por sua vez, caracterizava-se pela ausência das demandas advindas da manutenção da vida, afirmando-se como o "espaço" em que os homens podiam mostrar-se uns aos outros sem a desigualdade decorrente da privação, da força ou da violência. Ele era o "palco" que se configurava entre iguais, tão logo estes se colocassem em recíproca aparição, revelandose por atos e palavras, isentos de coerção ou privação. Duas características fundamentais o definam: a igualdade e a diferença. A primeira era necessária para que todos pudessem se comunicar e se compreender, constituindo um espaço comum. A segunda para que cada um deles pudesse se revelar, isto é, se distinguir dos demais, furtando-se a uma homogeneidade geral que, por princípio, recusaria toda possibilidade de aparição.

Revelação da diferença singular em meio à igualdade geral, esse

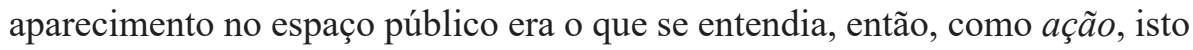
é, uma revelação livre e diversa por meio da qual "alguém" se apresentava ao mundo e aos outros. Distante do que viriam a ser suas figurações posteriores, a liberdade não se referia, pois, nem a uma querela da vontade - como "livre arbítrio" -, e nem a uma deliberação da razão - como "juízo" -, mas a essa capacidade de ação assegurado pelo espaço público e que, ao mesmo tempo, o assegurava. Nem imerso nas "trevas" do coração do homem e nem sujeito aos desígnios de uma racionalidade abstrata ${ }^{7}$, esse aparecer singular e desimpedido era possível apenas em um espaço que coadunasse coexistência e diferenciação. Agindo, cada singularidade se mostrava; mostrando-se, distinguia-se, revelando o "quem" de cada ato ${ }^{8}$. Era esse mostrar-se distintivo e imune à coerção o que se entendia, então, por liberdade.

É a partir dessa circunscrição que Arendt nos convida a uma aproximação surpreendente. Se a liberdade é uma ação alheia à opressão da força e às constrições da necessidade e de seus operadores utilitários, um ato que não

7 Conforme Entre o Passado e o Futuro, particularmente o ensaio O que é a Liberdade? (Arendt, 1997).

8 Nesse mostrar-se, o sujeito revelava-se não apenas por seus atos, mas, inseparáveis deles, por suas palavras. Como mostra Arendt, o que a liberdade dos antigos exigia era a indissociabilidade entre ação e discurso: só era efetivamente livre o ato que se mostrasse acompanhado de palavras capazes de lhe dar sentido e distinção. 
pode sofrer qualquer tipo de determinação, ela não pode ser compreendida senão como um "milagre" (Arendt, 1987, p. 191).

Trazendo para o núcleo de sua discussão um operador acentuadamente teológico, a afirmação parece inusitada para uma pensadora política do século $\mathrm{XX}$. A liberdade é um milagre, no sentido preciso do advento do novo, singular e imprevisível. A proposição encontra sua fonte em Agostinho ${ }^{9}$. Referindose principalmente $A$ cidade de Deus, Arendt defende que o filósofo teria reconhecido, no nascimento do homem no mundo, o surgimento daquilo que the seria mais estranho: um novo início. Diferente do princípio, que poderia admitir algo antes de si - como o "princípio do mundo", que teria sido precedido pelo surgimento dos anjos (Arendt, 1987, p. 190) -, o início significaria um começo absoluto, antes do qual nada haveria - "antes dele não havia nenhum" início não admitiria nada que o precedesse, nada como ele: iniciar é trazer ao mundo o absolutamente novo, e, por isso mesmo, único, necessariamente distinto de tudo que o antecedeu e o sucederá. As ideias de início e de distinção se entrelaçam, circunscritas ao redor da unicidade que todo começo implica. É o que permite à autora afirmar - como vimos acima - a ação como revelação, pois agir implica trazer ao mundo aquilo que de único o ser porta, o caráter inédito intrínseco ao começo que ele é e que o distingue necessariamente de todos os demais, afirmando sua diferença e sua singularidade. Iniciar é distinguir-se, necessariamente diferenciar-se, e, assim, revelar-se em sua singularidade.

A base para essa capacidade de iniciar, Arendt a reconhece na própria condição humana, enquanto ela própria é um início, um nascimento. É a "natividade", defende a autora, assegurada pelo nascimento, o fundamento ontológico da capacidade humana de agir e, com ela, da própria liberdade. $\mathrm{O}$ diálogo - e a subversão - com Heidegger é aqui claro e contundente. Recusando o que ela própria define como metafísicas da morte ${ }^{11}$, trata-se de se afastar da compreensão da condição humana como caracterizada, sobretudo, por sua finitude ou seu ser-para-a-morte, afirmando que são precisamente o nascimento

9 O diálogo de Arendt com Agostinho é constante ao longo de toda a sua obra, presente desde sua dissertação (Arendt, 1997) até $A$ vida do Espírito.

10 A citação de Arendt é praticamente literal. Nós a encontramos na seguinte passagem de A Cidade de Deus: "É indubitável, ademais, não poder crescer nem poder chegar ao termo de sua quantidade [o número de almas], sem ter princípio. E tal princípio, como ele, antes jamais existiu. Para que existisse, foi criado o homem, antes de quem não existiu nenhum" (Agostinho, 2012, p. 109).

11 Nessa direção, podemos lembrar aqui da leitura que a autora faz da filosofia contemporânea, particularmente da fenomenologia e de Heidegger, que, mesmo com avanços, padeceria de uma espécie de incapacidade intrínseca de formular um pensamento efetivamente político, justamente pela inaptidão em conceber o caráter plural da condição humana. Esse diagnóstico aparece tanto em seu ensaio O que é a filosofia da Existenz? (Arendt, 2002a), quanto em O interesse pela política no recente pensamento europeu (idem). 
e a capacidade de iniciar que a fundam e lhe dão sentido ${ }^{12}$, assegurando ao homem o "dom" de agir e, com ele, de existir entre os outros. Nascer é iniciar, mas, no caso da condição humana, essa característica é levada ao seu extremo: com o nascimento do homem, tem início um ser, ele próprio, dotado da capacidade de iniciar, ou seja, um "milagre" capaz de fazer "milagres": "Com a criação do homem, veio ao mundo o próprio preceito de início; e isto, naturalmente, é apenas outra maneira de dizer que o preceito da liberdade foi criado ao mesmo tempo, e não antes, que o homem" (Arendt, 1987, p. 190).

É essa capacidade de iniciar, ruptura de todos os processos deterministas e mecânicos, que caracteriza, enfim, o núcleo do que a autora compreende como liberdade. Imprevisível e improvável, ela é a instauração do novo que recusa toda uniformidade, tendo como única certeza sua necessária distinção. Ela se afasta, assim, de qualquer forma de força e violência - de determinação extrínseca - para afirmar-se como instauração e efetivação de "poder"13, no sentido preciso em que a autora propõe o termo ${ }^{14}$ : início de algo até então inexistente, tornando-o visível e narrável de diversos modos e por diferentes perfis; instauração de um momento novo na "teia" de relações humanas, dandothe possibilidade de expor-se, desdobrar-se e expandir-se. Trata-se, segundo ela, do potencial gerado a cada vez que os homens se reúnem na modalidade da ação e do discurso, criando uma realidade que, quase independente da materialidade, pode ampliar-se de modo praticamente ilimitado (Arendt, 1987). Se o espaço público é um campo relacional, sem barreiras e fronteiras materiais, cada novo ato, ao adentrar em sua dinâmica de reverberações, encontrava um horizonte quase inesgotável de expansão. Isso significa que, deixada por si mesma, a liberdade descobre em si um poder incomensurável: nutrindo-se da plasticidade do espaço público, sua capacidade de iniciar não encontra limites capazes de contê-la; inserida na "teia" humana, ela pode "ecoar" indefinidamente, desconhecendo qualquer moderação.

Esse potencial, afirma ela, sempre foi temido pelos homens, e grande parte das teorias políticas lhe buscou alguma contenção, em nome de uma "segurança" que não poderia admitir uma liberdade que, entregue a si mesma, teria poder suficiente para reiniciar tudo a cada instante, pondo em risco a estabilidade do mundo e de sua própria conservação. $\mathrm{O}$ dom de iniciar, de

12 Novamente uma inversão do pensamento heideggeriano.

13 Arendt estabelece uma diferença radical entre esses três registros: poder, força e violência, configurando um importante eixo de sua reflexão.

14 A noção de poder é amplamente trabalhada pela autora. Aqui a tocamos tangencialmente, lembrando que o poder apenas se estabelece em condições de liberdade e pluralidade, indissociável da ação e de sua capacidade de desdobramento. 
modo geral, foi historicamente compreendido como uma ameaça aos assuntos humanos e a sua permanência.

De fato, embora por uma compreensão diversa daquela defendida pela maior parte de tradição política, também Arendt reconhece um risco na ilimitação da liberdade, mas agora pela constatação da possibilidade dela tornar-se uma ameaça a si mesma. Se empregasse toda sua capacidade de iniciar em desfazer o que houvesse de já instituído, ela inviabilizaria sua própria existência, na medida em que não haveria mais mundo, uma rede de relações e de memória, que permitisse seu aparecimento e sua salvaguarda; a ação destruiria o espaço público e, com ele, sua própria possibilidade. De modo inverso, mas igualmente grave, a ausência de limites poderia conduzila ao risco oposto: sua capacidade de iniciar, uma vez instalada na rede das relações humanas, poderia condená-la a um desdobramento único e fatal. Se não encontrasse contenção, a ação inauguraria um início que não cessaria de afirmar-se, que não poderia ser detido ou remediado, impossibilitando qualquer iniciativa nova. Em um caso, a dissolução; no outro, a fatalidade. Em ambos, portanto, a liberdade se inviabilizaria, ou pela ausência de estabilidade ou pela ausência de renovação - como veremos, ou pela ausência de passado (e com ele continuidade) ou pela ausência de porvir (e com ele mudança).

Arendt reconhece, então, a necessidade e a existência de dois operadores, responsáveis por oferecer "contenções" ou "moderações" que impeçam essa autonegação da liberdade. Cabe enfatizar, nesse sentido, que se trata de uma necessidade intrínseca, isto é, não é por qualquer finalidade ou imposição externa que a liberdade deve ser "contida" - o que poderia legitimar formas de coerção ou, mesmo, de violência. Ao contrário, é sua própria configuração que exige essa moderação, como garantia necessária de que seu poder não inviabilize a si mesmo.

O primeiro operador, e novamente um surpreendente recurso para uma discussão política empreendida no epicentro do século XX, é o perdão. Foi Jesus, afirma Arendt, quem desvelou seu verdadeiro sentido e seu verdadeiro potencial. Ao contrário do que supõe a maior parte da tradição escolástica, seu principal ensinamento estaria em explicitar o sentido político do ato de perdoar, revelando-o como uma capacidade essencialmente humana. Não é Deus quem originariamente perdoa, mas os homens (Arendt, 1987): antes de uma

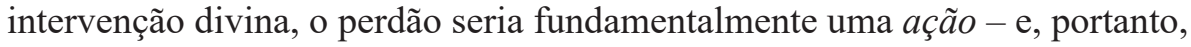
algo que implica pluralidade, mantendo-se indissociável da condição humana. A Deus, segundo a exegese proposta por ela, caberia a justa retribuição pelos feitos e pelos atos, reparando-os ou reequilibrando-os. É o homem, contudo, quem os perdoa. Pois perdoar, e essa é a maneira original pela qual Arendt 
interpreta o termo, é, antes de tudo, "des-obrigar" um ato de suas consequências e o agente de seus desdobramentos. Como vimos, se cada ação é um começo, e se esse começo, uma vez inscrito na rede de relações, tem o poder de ecoar ininterruptamente, um único início poderia, por princípio, gerar uma série sem fim de consequências. Se não houvesse uma forma de desvincularmonos dele, estaríamos condenados aos efeitos de nosso primeiro (e único) ato, do qual jamais nos libertaríamos. É preciso, pois, que haja a possibilidade de interromper o que iniciamos, sem o que perderíamos a própria capacidade de iniciar: é preciso que tenhamos a capacidade de perdoar.

Compreendido como essa possibilidade de recomeço - e de decorrente interrupção -, o perdão pouco tem a ver com uma moral teológica em seu sentido clássico, com uma concepção de bem ou mal, certo ou errado. Ao contrário, enquanto ação, e, portanto, intrinsecamente humano, ele se encontra inscrito na capacidade que os homens trazem de iniciar, mas agora no momento em que ela se volta "contra" si, tornando-se capacidade de se libertar e se desobrigar de si própria. O perdão, nesse sentido, é a única "reação" que não apenas reage, mas age de novo, literalmente, reiniciando. Perdoar, portanto, é interromper uma série de desdobramentos por meio de um novo início que desobriga os sujeitos do que foi feito, eximindo-os do peso de um passado que, do contrário, se cristalizaria na forma da fatalidade. Como descreve Arendt, o que mais teria surpreendido os fariseus não teria sido o fato de Jesus fazer milagres, mas o fato dele ser também capaz de perdoar.

Segundo ela, também o caráter intrinsecamente plural do perdão teria sido anunciado pela primeira vez por Jesus, ensinando que sua conformação humana implicava que ele apenas poderia se realizar fora de uma dimensão solipsista. Se todo ato tem como condição a pluralidade - a aparição e a relação com a alteridade -, o perdão só se efetiva ao repercutir no outro, modificando-o e desdobrando-se, inscrevendo-se na realidade do mundo e de suas relações. Não é apenas em mim que a ação que iniciei se encontra, não detenho todas as suas consequências e não é apenas sobre mim que elas incidem. Uma vez que ela é um aparecer no mundo e uma transformação dele, é ele que pode (ou não) desobrigá-la. Assim, é o outro quem me isenta das consequências de meus atos, assim como sou eu que posso isentá-lo do que ele (me) fez. Pelo perdão, os homens libertam-se uns aos outros, desengajando-se mutuamente de um passado que os tornaria incapazes de agir e iniciar novamente: como retomaremos adiante, através dele, eles reabrem o passado e asseguram um futuro.

Resta, então, o outro risco ao qual a imoderação do potencial da liberdade poderia conduzi-la: um reinício sem fim, reposto incontáveis vezes, que 
destruiria toda estabilidade e permanência. Nesse caso, seria o "lugar" de sua aparição e, com ele, de sua própria existência, que estariam sob ameaça. Razão pela qual não basta que a ação se modere com relação a sua capacidade de "manter" indefinidamente algo que iniciou, mas é preciso que ela o faça também com relação a sua capacidade de reiniciar tudo a cada instante. $\mathrm{Ou}$ seja, se o perdão é uma mediação em relação ao que foi feito, é preciso que haja também uma mediação em relação ao que há por fazer. Cabe, então, que a ação encontre um modo de abdicar de parte de sua potencialidade, de sua capacidade de desengajar-se inteiramente do passado, decidindo pela "continuação" do que foi iniciado, direcionando-se a favor da preservação do mundo e de si, resguardando-se frente à "imprevisibilidade" do futuro. É preciso, pois, que ela se comprometa, isto é, polarize-se em um sentido único, represando sua capacidade de iniciar: em termos arendtianos, é preciso que ela "prometa". A continuidade do mundo e dos atos exige que a liberdade não permaneça aberta a todo e qualquer empreendimento, mas que decida voltar-se a um (ou alguns) deles, configurando uma "ilha de certeza" no oceano de indeterminação que é o futuro. Dito em linguagem fenomenológica, a ação decide, e assim dá forma e sentido a um futuro que, deixado por si (caso isso fosse possível), permaneceria sem forma e relevo. Ela cria e sustenta um porvir, ao abdicar de todo (e qualquer) porvir, recusando a indeterminação completa por meio da determinação de si mesma. A promessa, assim compreendida, é a ação que se compromete com o futuro e, com isso, detém seu poder destrutivo; ato que envereda no porvir, abrindo-se a ele e determinado-se em sua direção.

Enquanto ação, de modo equivalente ao perdão, ela opera de modo fundamentalmente relacional. Assim como ele, trata-se de uma experiência entre sujeitos: é junto ao outro que me engajo alhures, que me comprometo com o que há de vir; é ele quem legitima meu compromisso e o valida, reconhecendome no porvir como aquele que sou agora, testemunhando a permanência de minhas ações e a continuidade de quem as realizou.

Podemos, assim, reconhecer no perdão e na promessa uma operação simétrica e correlata: enquanto o primeiro descompromete o poder ilimitado da ação, des-obrigando-a, a segunda lhe compromete o poder, engajando-a. $\mathrm{O}$ perdão modera a capacidade da ação de desdobrar-se e manter-se, e a promessa modera sua capacidade de iniciar e recomeçar. Ambos, portanto, represam um poder que, deixado por si, se anularia, ou porque a ação não poderia jamais mudar, nada negando, ou porque ela não poderia jamais continuar, nada afirmando. Nesse sentido, trata-se de dois momentos intrínsecos a ela, tão logo ela decide comprometer-se ou descomprometer-se, expressões de sua capacidade de, simultaneamente, abrir o passado e abrir-se ao porvir, 
assegurando sua própria existência. Lida nessa perspectiva, a liberdade pode ser descrita como uma tríade coesa, expressa, com precisão, em linguagem teológico-cristã: ela é milagre, perdão e promessa, configurando-se em três momentos inseparáveis. Ação que inicia, abre-se e compromete-se: em um único movimento, presentificação, distensão do passado e polarização rumo ao porvir.

É precisamente essa compreensão - e esse eixo de leitura - que nos permite sustentar a hipótese descrita no início deste ensaio, segundo a qual haveria, por sob as capacidades humanas mobilizadas por Arendt para descrever a liberdade, uma compreensão sobre a temporalidade, ainda que latente. Se a ação não pode ser apenas início, é porque há passado e preservação; se ela não pode encerrar-se nesse passado, é porque há porvir e mudança. Os tempos se implicam e se exigem, abrem-se um ao outro em recíproca reversibilidade. Sem passado, aquilo que foi iniciado não permaneceria, perdendo seu sentido e sua historicidade; sem futuro, cristalizar-se-ia, transposto à condição de determinismo. O passado se "congelaria" como fatalidade ou o porvir como eterno início. Desapareceriam as relações, o tempo se fecharia sobre o já sido ou sobre a dissolução. Em um caso, abdicar-se-ia da mudança, no outro, da conservação: ausência do passado ou ausência do futuro e, sobretudo, ausência da passagem de um ao outro.

Razão por que nos parece possível sustentar a hipótese de que a questão em torno da qual a descrição de autora gravita, mesmo tacitamente, é a necessidade do reconhecimento de uma articulação originária entre "permanência" e "mudança", afirmação de uma continuidade intrínseca ao tempo em simultaneidade com sua constante transformação. A partir dessa hipótese, o perdão e a promessa podem ser compreendidos como formas de articular as duas dimensões em um único movimento. Mais ainda, podem ser lidos como a explicitação da inseparabilidade e da recíproca constituição de uma pela outra: só há perdão porque é possível direcionar-se ao futuro e só há promessa porque é possível desobrigar-se do passado. A abertura ao porvir - e, portanto, a possibilidade de prometer - implica a abertura $d o$ passado - e, assim, a possibilidade de perdoar. Reciprocamente, o desengajamento do passado só pode realizar-se efetivamente na medida em que é possível voltar-se a um outro porvir. Garantias de um presente que só pode assegurar-se como início mantendo-se tensionado entre aquilo que preserva e aquilo que modifica. Nesse sentido, o poder de iniciar se vê configurado na tensão entre um passado que ele transforma e um futuro que ele afirma, atando os três momentos temporais de forma inextrincável. Agir é temporalizar, é libertar-se, iniciando, perdoando e prometendo. Unidade simultaneamente diferenciada e coesa. 


\section{O diálogo com Sartre e Merleau-Ponty}

Essa compreensão sobre a temporalidade, latente nas análises de Arendt sobre o "milagre", o perdão e a promessa, permite-nos propor uma aproximação. A "opção" da autora pelo reconhecimento de certa articulação entre "continuidade" e "mudança" ou, ao menos, de um diálogo entre as dimensões temporais e, mais ainda, o reconhecimento de um vínculo intrínseco entre temporalidade e liberdade permite-nos situá-la dentro de um debate mais amplo entre outros dois autores, também centrais, contemporâneos a ela e não de todo distantes de seu pensamento: Sartre e Merleau-Ponty ${ }^{15}$. O que pretendemos, agora, é a circunscrição de um horizonte comum de pensamento e de um campo de investigação, nos quais se torna possível explicitar um "estado da questão" que os aproxima, uma direção de reflexão, ao menos em parte, partilhada.

Como se sabe, as questões concernentes à temporalidade e à liberdade ocupam no pensamento contemporâneo um lugar central. Particularmente em Sartre e Merleau-Ponty, elas adquirem notório relevo - desdobramento incontornável da matriz fenomenológica comum a ambos, notadamente Husserl e Heidegger. Em linhas bastante sucintas, o núcleo que aqui trabalharemos diz respeito precisamente a essa questão sobre a existência (ou não) de uma continuidade intrínseca às dimensões temporais. É nessa questão - entre outras - que divergem Sartre e Merleau-Ponty, conduzindo-os, como veremos, a diferentes compreensões sobre a liberdade.

Em O Ser e o Nada, Sartre propõe, como uma de suas questões principais, a compreensão da liberdade a partir de uma proposição ontológica bastante precisa: a realidade humana, enquanto consciência, é descrita como puro nãoser; já as coisas, o mundo, aquilo que lhe aparece, como puro ser, positividade plena. As duas "modalidades" ontológicas operam necessariamente em regime de correlação - herança do pensamento husserliano ${ }^{16}$-, mas sem qualquer possibilidade efetiva de fusão (Sartre, 1997, p. 64). É pela realidade humana que o nada vem ao ser, mas isso implica compreender, antes de tudo, que se trata de duas regiões distintas, cuja vinculação não admite qualquer motivação; ao contrário, apenas uma consciência que é perpétuo "desgarramento", distância de "si' e negação, pode suportar a negatividade em seu sentido autêntico. Ela

15 Conforme a circunscrição proposta neste artigo, apoiar-nos-emos sobretudo em O Ser e o Nada de Sartre e A Fenomenologia da Percepção de Merleau-Ponty.

16 A esse respeito, ver especialmente a discussão proposta por Sartre na Introdução de O Ser e o Nada. Sobre a relação entre Sartre e Husserl, destacamos o livro de Carlos Alberto sobre o modo como a herança fenomenológica deixada por Husserl figura em seus "dissidentes existenciais” (Moura, 2001). 
opera nadificando o ser em-si, negando a positividade e a indiferença que o configuram, fazendo-o ser para ela, na forma do sentido ou da significação. Como é trabalhado do decorrer de todo o livro, por diferentes encaminhamentos: "[...] a consciência sempre pode ultrapassar o existente, não em direção a seu ser, mas ao sentido desse ser" (Sartre, 1997, p. 35). O sentido não nasce a partir do ser, mas a partir do movimento de transcendência por meio do qual a consciência o nadifica, operando como projeto que o ilumina e o retira da indiferença do em si.

Isso significa que, tomado por si mesmo, o ser não oferece à consciência qualquer forma de significação ou de determinação, incapaz de propor-lhe um sentido intrínseco, permanecendo tributário de sua atividade para constituirse. É esse um dos operadores por meio dos quais a liberdade sartreana se vê assegurada: a inteira distinção entre o Ser e o Nada a isenta de toda opacidade, implicação ou resistência. Por se tratar de duas modalidades ontológicas distintas, ainda que em recíproca correlação, uma não pode efetivamente operar sobre a outra, o ser não pode determinar o não ser, e a liberdade não se encontra constrangida por nada que lhe seja "exterior". A liberdade não pode ser determinada por nenhuma causa, nem mesmo por ela própria, pois a nadificação que a configura, enquanto "fonte de si mesma", sempre se encontra apartada de tudo o que ela foi, de toda dimensão de ser.

Assim compreendidos, a relação originária entre o Ser e o Nada - que, ao mesmo tempo, os correlaciona e cinde - é a nadificação (Sartre, 1997, p. 135). Vem desse solo ontológico a concepção do autor sobre a ação. Se, para Arendt, agir é reabrir o mundo, impactar de modo novo a rede de relações humanas, para Sartre a ação é, antes de tudo, um processo de nadificação. Agir é projetar um não-ser que, por princípio, distingui-se de todo ser em-si, do mundo e das coisas, instaurando uma negatividade a partir da qual o sujeito ilumina e valora o ser que o circunda. Como nos mostra Franklin Leopoldo e Silva: "A realidade humana se define pela sua falta constitutiva; escolher e agir é moverse $e m$ direção à falta, $n a$ falta, isto é, no vazio de onde brota a ação e a partir do qual se constitui o valor" (2010, p. 21). A noção de projeto é aqui fundamental e, na verdade, uma expressão da negatividade própria à consciência: "Mas, precisamente, é a nadificação que origina a transcendência concebida como vínculo original entre o Para-si e o Em-si” (Sartre, 1997, p. 135).

Negar é sempre, em alguma medida, projetar-se, transcender. Ao agir, a consciência nega o que é, projeta-se em direção a um não ser instaurado por ela, e, a partir desse negativo, opera uma segunda negação, a do ser como ele agora lhe aparece, em relação ao seu projeto. Em termos de ação, isso equivale a afirmar que é a decisão que faz aparecer o sentido da situação e os móbeis 
através dos quais se realizará; é ela quem cria os motivos de seus atos, e não o contrário, como supunha a maior parte da Tradição (Sartre, 1997, p. 536 e segs.). A decisão constitui o valor efetivo do Ser, tornando-o para ela situação ${ }^{17}$. Um conhecido exemplo dado por Sartre refere-se à condição do operariado.

Não são as dificuldades do trabalho, da condição social, e nem mesmo a luta de classes que fazem com que o operariado aja, isto é, não é o peso de sua situação que o motiva a decidir pela revolução. Ao contrário, é a partir do momento em que ele projeta um outro estado de coisas - um não ser -, que esse projeto faz com que sua situação lhe apareça como insuportável e, a partir disso, como motivo. Ou seja, é ao negar sua condição, pela projeção de um estado de coisas diverso, que o sujeito a "ilumina", tornando-a algo a ser transformado. O projeto faz do ser sentido e motivo, e é ele, portanto, quem mobiliza a ação, decidindo sobre o sentido daquilo que lhe aparece.

Em termos de temporalidade, isso significa que é do porvir que reflui o sentido dos temporas e de sua articulação. Em linhas mais gerais, a compreensão do caráter de desgarramento da consciência e de sua "constituição" fundamentalmente negativa implica, por um lado, a impossibilidade de uma continuidade intrínseca ao tempo e, por outro, a necessária afirmação de certa primazia do porvir - como veremos, é no tempo que se encontra a explicitação última da compreensão sartreana sobre a ação ${ }^{18}$. É o porvir, entendido como projeto ou transcendência, quem "ilumina" o presente e o passado, fazendo-os surgir à luz da liberdade da consciência, isentos de significação ou opacidade própria. E é aqui que se pode reconhecer um passo decisivo na descrição de Sartre, em uma de suas proposições que mais o afasta de parte considerável da tradição fenomenológica: a tese de que há uma ruptura na temporalidade.

Enquanto meu estado presente for prolongamento do estado anterior, qualquer fissura pela qual puder deslizar a negação estará inteiramente fechada. Todo processo psíquico de nadificação implica, portanto, uma ruptura entre o passado psíquico imediato e o presente. Ruptura que é precisamente o nada (Sartre, 1997, p. 70).

A concepção de tempo defendida por Sartre não pode admitir o que ele descreve, por um lado, como "continuidade do fluxo" e, por outro, como "intercalação brusca" de um elemento exterior. Buscando um denominador entre unidade e dispersão, o autor apoia sua descrição no processo de nadificação

17 A esse respeito, sobre o modo pelo qual a liberdade institui valores, e assim se transpõe para uma dimensão ética, ver especialmente Sobre Ética e Literatura, de Franklin Leopoldo e Silva.

18 A relação entre ontologia e temporalidade é questão central no pensamento Sartre. Aqui, conforme o tema proposto, nós a abordaremos indiretamente. 
originário da consciência, emergência desse nada que toma distância de seu passado, sem o que, segundo ele, a temporalidade sequer poderia figurar. Essa distância, contudo, se impede a permanência, ao mesmo tempo a preserva da completa dispersão, já que implica que a consciência necessariamente mantenha relação com "seu" passado, justamente como "separado dela por um nada" (Sartre, 1997, p. 72) - como aquilo que ela não é e não a determina. Ou seja, a consciência instaura uma relação de negação, o que significa, ao mesmo tempo, ruptura e vinculação.

Nesse sentido, é importante destacar o esforço de sua descrição em manter essa tensão entre a "separação" instaurada pelo nada e o reconhecimento da simultaneidade existente entre as dimensões temporais. Há unidade dos temporas, sem o que a própria noção de tempo se esvaziaria, mas essa unidade não pode implicar "continuidade", uma vez que é a negação quem instaura o devir temporal, sendo do porvir projetado que a temporalidade "reflui": a negatividade impede o tempo de configurar-se como puro continuum - condição necessária para que a liberdade seja preservada sem condicionamentos. Se a consciência é negação, ela não admite qualquer motivação - ou mesmo configuração - pelo passado "ele próprio"; impossível padecer algo.

Desse modo, não é o passado que se desdobra no presente, não é ele enquanto motivo ou o móbil - que implica algo ao fluxo ${ }^{19}$, e sim a consciência que o faz desdobrar-se, fazendo dele o sentido que sua negação lhe confere. É como se cada presente instaurasse uma quebra - ou, mais precisamente, uma negação - na aparente "linearidade" do tempo, configurando aí uma fenda por meio da qual a liberdade se exercesse. Não há, nesse sentido, uma articulação própria ao tempo, se por isso entendermos um movimento espontâneo de conservação e de continuidade, mas uma ação sempre renovada da consciência que decide (ou não) por essa permanência. Se é pela negação que a temporalidade opera, a preservação de algo exige que o projeto decida por ela, criando-a e sustentando-a. A unidade permanece, assim, atada a uma negatividade que não lhe permite realizar-se efetivamente, sempre feita e refeita a cada novo ato, assegurada inteiramente pela ação livre da consciência, explicitando a imbricação originária que reúne temporalidade e liberdade: "A liberdade é o ser humano colocando seu passado fora de circuito e segregando seu próprio nada" (Sartre, 1997, p. 72). E ainda:

O que separa o anterior do posterior é precisamente nada. E este nada é absolutamente intransponível, justamente por ser nada [...] Assim, a condição para a realidade humana 
negar o mundo, no todo ou em parte, é que carregue em si o nada como o que separa seu presente de todo seu passado (Sartre, 1997, p. 71).

Esse é um dos eixos em que o pensamento de Sartre distancia-se largamente do de Merleau-Ponty. Embora seja comum o tratamento de ambos como muito próximos - como o faz, por vezes, a própria Hannah Arendt (Arendt, 2002b, p. 83) -, julgamos possível reconhecer diferenças profundas entre eles. Aqui, conforme o tema proposto, nosso foco se manterá sobre a discussão a respeito da articulação entre continuidade e mudança na dinâmica temporal.

Para Merleau-Ponty, afastando-se de Sartre, a relação entre a consciência e seu entorno - o mundo, a alteridade, a linguagem - não pode ser descrita em termos de uma dualidade entre o ser e o nada. Desde o início divergindo do encaminhamento proposto por ele, Merleau-Ponty busca o recurso a um solo originário, pré-dual, em que a dicotomia característica do "pensamento objetivo" (seja ele intelectualista ou empirista) ainda não tenha se instaurado, recusando a cisão entre o sujeito e aquilo que lhe seria, supostamente, "outro" - compreendido aí também o passado. A tentativa de uma "explicação" ou de uma "análise" da experiência através das categorias dualistas formuladas pelo pensamento moderno é denunciada por ele por diversos encaminhamentos como intrinsecamente insuficiente.

No que concerne à questão da liberdade, um dos temas mais importantes da obra do autor, o debate com Sartre é constante ao longo de toda sua filosofia, sendo explicitamente assumido no decorrer de toda a Fenomenologia da Percepção, com especial ênfase em seu último capítulo, no qual a questão se torna tema central.

O capítulo se inicia exatamente pela reconstrução do argumento sartreano, em alguns momentos de modo quase literal. Partindo da impossibilidade de supor a causalidade como determinante da liberdade - posição compartilhada por ambos -, Merleau-Ponty refaz o percurso de conclusões extraídas por Sartre. De início, retoma a proposição segundo a qual a consciência se reconhece como um "fluxo anônimo", um "projeto global", em que não há "estados de consciência ou qualificações possíveis". Ela se descobre um "poder de evasão" que não admite limite ou determinação: sua universalidade e generalidade desconhecem restrições, desembocando em uma liberdade absoluta.

Nessa perspectiva, torna-se impossível falar em situações livres e situações não livres, ou mesmo em uma espécie de atenuação da liberdade. Ou ela é total ou não é; não se admitem formas particulares, o mais ou o menos, variações. Como decorrência, não é apenas à causalidade que seria necessário renunciar, mas também à ideia de motivação, uma vez que o "pretenso motivo não pesa em minha decisão, ao contrário é minha decisão que lhe empresta sua força" 
(Merleau-Ponty, 1994, p. 582). Se é a partir da ação que se desdobram os motivos (do nada que emerge o ser), eles não são senão emblemas de seu poder de criar para si um contexto e uma situação. Mesmo o ato voluntário ou os supostos obstáculos não são mais que desdobramentos dela, e não chegam jamais ao seu núcleo. Como descreve Sartre em O Ser e o Nada, um rochedo só aparece como intransponível, só adquire sentido, para um sujeito que o recorta da indiferença do em si e o ilumina por meio de seu projeto de escalálo. $\mathrm{O}$ argumento da alteridade, por sua vez, tampouco invalidaria a liberdade em sua completa autonomia. Ainda que seja inegável que eu seja para outrem, isso em nada desfaz a lógica segundo a qual "permaneço livre de pôr outrem como uma consciência" (Merleau-Ponty, 1994, pp. 582, 583), isto é, sou eu quem faz o outro ser para mim, de modo que a ação que porventura ele exerça sobre mim não é senão a expressão segunda de um poder que eu lhe conferi e que permanece inteiramente tributário de minha decisão. Em todos os âmbitos, o sujeito se reconhece como fonte originária de todo processo de significação.

Reconstruído o percurso geral, a conclusão a que chega Merleau-Ponty, contudo, é diametralmente oposta à de Sartre, tornando explícita a distância que os afasta: tal reflexão tornaria a liberdade impossível. A primeira impossibilidade decorrente dela - e elemento particularmente importante para nossa discussão seria exatamente o fato de que a noção de "ação livre" despareceria da reflexão sartreana:

Com efeito, se a liberdade é igual em todas as nossas ações e até mesmo em nossas paixões, se ela não tem medida comum com nossa conduta, se o escravo testemunha tanta liberdade vivendo no temor quanto rompendo suas correntes, não se pode dizer que exista nenhuma ação livre, a liberdade está aquém de todas as ações [...], já que a ação livre, para ser revelável, precisaria destacar-se sobre um fundo de vida que não fosse ou que o fosse menos (Merleau-Ponty, 1994, p. 585).

Reencontrando um operador central da reflexão de Merleau-Ponty, a liberdade, para aparecer e ser no mundo, precisa destacar-se do fundo, ganhar relevo, isto é, instaurar uma diferença por meio da qual possa ser percebida. A existência da ação implica sua relação com um conjunto, sua configuração como momento de uma articulação mais ampla em relação à qual adquire forma e sentido. É a noção de estrutura - aqui introduzida de modo breve, mas inequívoco - que se opõe à possibilidade de uma liberdade abstrata ou informe ${ }^{20}$. Sem ela, a existência do ato se torna puro formalismo. 
Seria exatamente o que ocorreria com a liberdade sartreana. Sem diferenciação e relação possíveis, ela jamais se tornaria uma realidade perceptível e tangível, um acontecimento, situando-se aquém do tempo e do espaço. Ela recuaria do plano da existência e passaria ao de "natureza" primordial - perderia sua condição humana, convertendo-se em princípio abstrato (Merleau-Ponty, 1994, p. 585): em termos ontológicos, a ausência de uma "passagem" que a permitisse transitar entre o ser e o não ser a privaria da possibilidade de ser no mundo. Ela deixaria, então, de ser um "fazer" no sentido merleau-pontyano, isto é, precisamente uma passagem, modalização do ser e figuração de uma realidade participável pelos outros. ${ }^{21}$ Nesse sentido, a recusa de Merleau-Ponty em relação à concepção sartreana de liberdade reflete não uma simples divergência pontual, mas uma compreensão ontológica claramente diversa.

É o que confirma a discussão sobre a ideia de "escolha". Segundo o filósofo, também ela "desapareceria" do pensamento de Sartre. Para que haja escolha, defende Merleau-Ponty, é preciso que haja algo que a liberdade escolha e no qual veja um emblema de si mesma, isto é, que haja um comprometimento com aquilo que se decide, um investimento que faça dele uma situação ou um campo. Não basta a liberdade fazer algo ser para ela como motivo; é necessário que ela se envolva em sua dimensão existencial, colocando a si mesma em condição de engajamento: "A própria noção de liberdade exige que nossa decisão se entranhe no porvir, que algo tenha sido feito por ela, que o instante seguinte se beneficie do precedente e, sem ser necessitado, seja pelo menos solicitado por este" (Merleau-Ponty, 1994, p. 586)

Retornando à questão central deste estudo, a noção de liberdade exige sua participação em uma dinâmica temporal - precisamente como aquilo que lhe permitir estruturar-se, assumindo forma e unidade. Para isso, como cabe examinar agora, é preciso que o tempo não seja uma soma de momentos discretos e independentes, mas um fluxo ou uma passagem espontânea e instituinte.

Retomando aquilo que havia sido longamente problematizado em seu capítulo sobre o temporalidade - e, na verdade, em toda a Fenomenologia da Percepção -, Merleau-Ponty compreende que o tempo opera como um fluxo cuja unidade provém de sua dinâmica intrínseca, síntese de transição assegurada pela própria configuração originária de seus elementos. Cada momento, nele,

21 Importante destacar que argumento semelhante é usado - então de maneira explícita - nos cursos sobre $A$ Instituição, quando o filósofo se ocupa precisamente da passagem do sonho à vigília, e da relação entre a consciência onírica e a perceptiva, uma vez mais em debate com as posições de Sartre. 
não é uma positividade discreta e autônoma, uma entidade isolável, mas uma abertura e uma passagem aos outros, sua antecipação e retomada - como horizonte de passado e de porvir -, em relação aos quais ele não é senão uma diferença. Ao fazer passar um momento presente ao passado, a temporalidade não o "expulsa do ser"; antes, ela o distende, intenciona, "conserva-o ainda em mãos" e, assim, o preserva como horizonte retido e como antecipação do que estava por vir. É todo o fluxo que se move e se modifica, de modo que o presente se transforma em passado e o porvir que ele gestava se transforma em presente. Nessa dinâmica única, o sentido de cada momento se estabelece de acordo com a relação que estabelece com os demais. Unidade que se autodiferencia e, por isso mesmo, se conserva, a temporalidade preserva transformando, e modifica preservando: unidade da e na mudança (não mais, portanto, a unidade estática da identidade, mas a unidade dinâmica de seu próprio processo de diferenciação). Transitividade originária que se encontra na base da ontologia latente na reflexão de Merleau-Ponty22 (Merleau-Ponty, 1994, pp. 563, 564).

É desse modo que a temporalidade assegura a existência de algo, ao instituir um momento cuja presença, por princípio aberta e transitiva, será perpetuamente reafirmada em cada um dos demais, que não são senão uma transformação e uma reconfiguração sua e, de modo mais geral, de todo o fluxo. Compreendida a partir desse horizonte, a liberdade não pode ser concebida como um início absoluto ou uma negatividade pura, mas como inscrita nessa configuração mais ampla, que não provém inteiramente de si e que ela não esgota. Cada ato singular instaura um movimento, dá-lhe início, mas isso não significa que ele o sustente absolutamente - por decisões instantâneas - ou que o faça emergir do nada, como uma ruptura com o que a antecedia. A abertura estrutural de um momento ao outro impede a suposição de uma negatividade extrínseca como elemento configurador do tempo e dos atos. Contra a negação defendida por Sartre, a abertura proposta por Merleau-Ponty; contra a ruptura, a transição (Merleau-Ponty, 1994, p. 586).

Não há, pois, negação completa na temporalidade merleau-pontyana e, por conseguinte, nenhum hiato em que uma liberdade absoluta pudesse aparecer, desfazendo uma articulação que dependesse apenas de sua atividade. A ação não opera como "recusa" ou "quebra" do passado, mas como reconfiguração dele: ela assume um passado que, por si mesmo, já se oferecia de modo aberto

22 Sobre a questão da ontologia no pensamento de Merleau-Ponty, há um intenso debate entre os estudiosos. Em linhas gerais, há duas correntes principais: uma que compreende não haver uma perspectiva ontológica no início de sua obra, e cujo expoente principal é Renaud Barbaras; e outra que reconhece a presença de uma ontologia desde seu início, divergindo então sobre a compreensão de seu lugar e sentido. Conforme mostra a discussão aqui em curso, aproximamo-nos da segunda vertente. 
e referencial, exigindo um porvir. Entre eles, opera uma espécie de "pacto" e de reversibilidade originários. Um importante exemplo descrito por MerleauPonty - explicitamente construído a partir de (e contra) Sartre - é a questão do operariado (Merleau-Ponty, 1994, p. 593 e segs.), que discutimos acima. Ainda que se aperceba de sua situação, se mobilize, e mesmo que faça a revolução, um burguês que se torne operário será sempre um "burguês-tornado-operário", isto é, seu presente será sempre uma resposta e uma reconfiguração de seu passado. Tornar-se operário não significa negar um passado burguês ou, de modo mais geral, uma situação e um horizonte temporais, mas reestruturá-los, polarizando-os em um sentido novo, que os transforma e, por isso mesmo, os conserva. As ações do sujeito necessariamente moldam o fluxo, justamente porque ele próprio se oferecia como por "moldar": nós padecemos o tempo não como fatalidade, mas como exigência de desdobramento, e é sempre em relação a essa passividade originária que a liberdade opera, reconfigurando aquilo que a solicita.

A existência do ato livre envolve sua participação nessa dinâmica espontânea cuja transitividade o situa e implica originariamente - e é, assim, que a configuração temporal reúne, intrinsecamente, continuidade e mudança, fazendo com que a liberdade não possa exercer-se senão em relação a algo que a ultrapassa, transforma e conserva. A esta "estrutura híbrida" - e à decorrente "torção" operada no pensamento sartreano - Merleau-Ponty encontra uma formulação precisa, justamente ao tomar como "eixo" aquilo que Sartre recusava como "monstruoso": "Uma espontaneidade 'adquirida' de uma vez por todas que 'se perpetua no ser em virtude do adquirido'. Eis exatamente o tempo e eis exatamente a subjetividade” (Merleau-Ponty, 1994, p. 573).

Se retornarmos, então, ao ponto do qual partimos, podemos enfim compreender de modo mais claro o tema que propusemos - a relação entre mudança e continuidade na dinâmica do tempo e suas implicações para a compreensão da liberdade -, e em que medida ele nos permite reconhecer uma proximidade entre Arendt e a fenomenologia.

Como vimos, nos três autores trabalhados, cabe à descrição do tempo iluminar a compreensão da liberdade, assegurando à ação um caráter fundante e não determinado, intrínseco à própria condição humana. Nos três, seja por negação, seja por imbricação, tal liberdade se mantém em relação originária com o mundo, sem em momento algum subordinar-se a ele; nos três casos, ainda, o sentido com o qual o agente se defronta permanece atado ao modo pelo qual seu ato institui um porvir, seja de modo absoluto (como em Sartre), seja de modo situado e histórico (como em Merleau-Ponty e Hannah Arendt). Em 
uma palavra: o eixo que reúne os três autores gravita em torno da compreensão de que agir é temporalizar.

Estabelecido esse horizonte comum, podemos reconhecer, então, em seu interior, uma espécie de bifurcação - conforme o sentido e o "lugar" que a negação ocupa frente à temporalidade -, e somos conduzidos a dois encaminhamentos claramente distintos: de um lado, Hannah Arendt e MerleauPonty; de outro, Sartre.

Como vimos, a compreensão da ação por meio das concepções de perdão, milagre e promessa permite entrever, em Arendt, a presença tácita da temporalidade, entendida sobretudo como dinâmica que, simultaneamente, se conserva e se transforma. Perdoar é abrir a mudança, prometer é assegurar a continuidade. Mais ainda, como discutimos, o próprio perdão assegura a continuidade, pois um tempo que não mudasse, que não se abrisse ao porvir, "congelaria", assim como é a própria promessa quem assegura a mudança, uma vez que um tempo que não se engajasse em um porvir novo, não poderia desobrigar-se do passado. Sem a relação de um com o outro, haveria apenas dissolução ou cristalização. Como pura mudança ou pura conservação, se obstruiria o fluxo, e não haveria mais propriamente temporalidade, um "vir a ser" e um "deixar de ser". Para que haja continuidade $e$ mudança, é necessário libertar-se simultaneamente do determinismo do passado e da indeterminação do porvir - da fatalidade e da gratuidade puras. Liberdade que jamais é inteiramente realizável, sempre tensionada entre aquilo que renova e aquilo que preserva.

É nesse sentido, sobretudo, que supomos Arendt mais próxima de MerleauPonty do que de Sartre. Pelo reconhecimento de um tempo único que se diferencia e, ao fazê-lo, preserva-se e confirma-se: mudança e unidade reciprocamente constituintes - e não mais excludentes, como supunha a Tradição. Fazer milagres, perdoar e prometer são três momentos de uma só dinâmica - a ação em seu sentido pleno -, assim como passado, presente e porvir são dimensões de um só "fluxo", a transitividade única que se singulariza em momentos diversos. Como em Merleau-Ponty, o tempo para ela opera diferenciando-se e reunindo-se, distendendo-se em momentos que, simultaneamente, o modificam e o preservam. Como ele, Arendt parece reconhecer que é apenas participando dessa articulação intrínseca à temporalidade que a liberdade pode se instaurar, aparecendo no mundo como uma ação que subverte o passado e o porvir, aquém da alternativa entre conservação e ruptura; configuração que faz da liberdade uma realidade, inscrita na teia humana que entretece, irremediavelmente, o que há por vir e o "já sido". 
Já em Sartre, claramente assumindo direção contrária, é precisamente esse "enredamento" da liberdade o que a tornaria inconcebível. Distante tanto de Arendt quanto de Merleau-Ponty, sua compreensão é inversa: a afirmação de uma continuidade intrínseca aos momentos do tempo significaria a própria recusa da ação livre, pois implicaria um horizonte em relação ao qual ela necessariamente teria que situar-se, solo que a configuraria: em termos ontológicos, tratar-se-ia de uma contaminação do nada pelo ser e, assim, de uma destituição da negatividade que a caracteriza. Ao contrário, é preciso compreender a temporalidade como operação fundamentalmente negativa e, nesse sentido, como garantia de uma liberdade que se afirma como puro poder de ruptura. Não há articulação espontânea e nem conservação intrínseca no tempo: na formulação sartreana, é o negativo quem decide (ou não) pela permanência, é ele quem a põe de modo inteiramente livre e imotivado. $\mathrm{O}$ tempo, aqui, não é transição, mas, sobretudo, negação.

Assim, se em Arendt, como vimos, a liberdade também tem um caráter inaugural, imprevisível e indeterminável, resta que esse início necessita de um espaço em que possa figurar, uma teia de relações e de memória que o legitime como tal, distinguindo-o de todos os demais: ela permanece, assim, em algum grau, condicionada. Do mesmo modo, se em Merleau-Ponty a liberdade também não pode encontrar-se determinada por nenhum elemento exterior, resta que ela necessita de um campo, de um passado, nos quais possa figurar, estruturando-se como realidade ao subverter aquilo que incorpora: ela permanece, assim, em algum grau, situada. Em Sartre, ao contrário, é a própria liberdade que põe o passado e o sentido de seu entorno; é ela quem constrói a permanência e, nesse sentido, quem decide pela conservação ou pela mudança: ela se afirma, assim, como absoluta.

Desse modo, reencontramos as duas questões descritas no início deste ensaio: de um lado, o horizonte comum aos três autores; de outro, dois encaminhamentos quase antagônicos para uma problemática semelhante, fazendo-nos compreender que a trama que compõe o solo fenomenológico é mais complexa e menos identitária do que por vezes se supõe. De todo modo, seja o tempo compreendido como transitividade, seja como negação, o eixo que o reúne irremediavelmente à liberdade é partilhado pelos três autores, e é isso que nos permite explicitar a proximidade de Arendt com a fenomenologia e com alguns de seus grandes temas. Tensionado entre temporalidade e liberdade, esse arco fenomenológico oferece uma das grandes matrizes pelas quais o pensamento contemporâneo busca enfrentar o legado advindo da Tradição sobre os incansáveis embates entre a Fortuna e a condição humana, entre determinismo e autonomia. 


\section{Referências}

AGOSTINHO. “De Civita Dei”. Trad. Oscar Paes Leme. Rio de Janeiro: Vozes, 2012. Parte II

ARENDT, H. "The life of the mind". Trad. Antônio Abranches. Rio de Janeiro: Relume Dumará, 1991. [Harcout Brace, 1978].

. "The Human Condition". Trad. Roberto Raposo. Rio de Janeiro: Forense

Universitária, 1987. [Chicago, 1958].

. "Between Past and Future". New York: Viking Press, 1961.

. "O conceito de amor em Agostinho". Lisboa: Instituto Piaget, 1997.

. “O que é a filosofia da Existenz?". In: ARENDT, H. A Dignidade da Politica.

Rio de Janeiro: Relume Dumará, 2002a.

. "O interesse pela política no recente pensamento europeu". In: ARENDT, H.

A Dignidade da Política. Rio de Janeiro: Relume Dumará, 2002b.

BARBARAS, R. "Merleau-Ponty et la Psychologie de la Forme". Les Études philosophiques, Nr. 2, 2001.

BENHABIB, S. "Feminist theory and the concept of public space in Hannah Arendt". In: History of the Human Sciences, 1993.

. "The Destruction of the Public Sphere and the Emergence of Totalitarism". In:

The reluctant modernism of Hannah Arendt. Oxford: Lanham: Rowman \& Littlefield Publishers, 1996.

BIMBENET, E. "De la science à la philosophie". In: Les Cigognes de la philosophie. Paris: L'Harmattan, 2002.

DUARTE, A. "Poder, violência e revolução no pensamento político de Hannah Arendt". Cadernos de Filosofia Alemã, Vol. 21, 2016.

MERLEAU-PONTY, M. "Phénoménologie de La Percetion”. Trad. Carlos Alberto Ribeiro de Moura. São Paulo: Martins Fontes, 1994. [Gallimard, 1945].

"L'institution. La passivité". Paris: Belin, 2003.

"La Structure du Comportement". Paris: PUF, 1967.

MOURA, C. A. R. "Racionalidade e crise". São Paulo: UFPR, 2001.

PITKIN, H. "Justice. On relating private and public". Political Theory, Vol. 3, Nr. 9, pp. 327-352, 1981.

SARTRE, J.-P. “L'imaginaire”. Paris: Éllipses, 1999.

. "O Ser e o Nada". Rio de Janeiro: Vozes, 1997.

SILVA, F. "Ética e Literatura em Sartre". São Paulo: UNESP, 2004.

. "Literatura, ética e política em Sartre". Teresa, São Paulo, Nr. 10-11, 2010. 